\section{Géneros}

Multidisciplinary loutnal of Gende Studies
Hipatia Press

www.hipatiapress.com

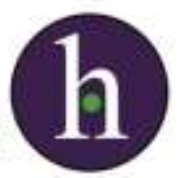

Instructions for authors, subscriptions and further details:

http://generos.hipatiapress.com

\title{
El nuevo ideal del amor en adolescentes digitales. El control obsesivo dentro y fuera del mundo digital.
}

Carmen Martín Gómez ${ }^{1}$

1) Universidad Loyola Andalucía. Spain

Date of publication: October $25^{\text {th }}, 2015$

Edition period: October 2015 - February 2016

To cite this article: Martín Gómez, C. (2015). El nuevo ideal del amor en adolescentes digitales. El control obsesivo dentro y fuera del mundo digital [Review of the book]. Multidisciplinary Journal of Gender Studies, 4(3), 856858. doi: 10.4471/generos.2015.1719

To link this article: http://dx.doi.org/10.4471/generos.2015.1719

\section{PLEASE SCROLL DOWN FOR ARTICLE}

The terms and conditions of use are related to the Open Journal System and to Creative Commons Attribution License (CC-BY). 
GÉNEROS-Multidisciplinary Journal of Gender Studies Vol. 4 No. 3 October 2015 pp. 856-858

\section{Review}

Rodríguez, N. (2015). El nuevo ideal del amor en adolescentes digitales. El control obsesivo dentro y fuera del mundo digital. Bilbao: Desclée De Brouwer. ISBN: 9788433027740.

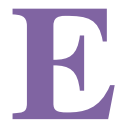

n el libro recientemente publicado El nuevo ideal del amor en adolescentes digitales. El control obsesivo dentro y fuera del mundo digital, su autora, Nora Rodríguez, intenta ofrecer una perspectiva global acerca de las relaciones afectivo-sexuales que se establecen entre chicos y chicas adolescentes en la actualidad, focalizándolas en las interacciones a través del ciberespacio.

La autora postula el enamoramiento como un acto de consumo más dentro de la sociedad del siglo XXI, donde el cuerpo de la mujer es cosificado. Expone como la construcción social del amor en los últimos años está caracterizada por el sufrimiento y la indiferencia, percibidos ambos como elementos de excitación llevando a las chicas a un papel pasivo en las relaciones. Esta situación contribuye a que tanto chicos como chicas, se sientan héroes y heroínas ante historias de amor consideradas difíciles, y a definir la relación de noviazgo y compromiso a partir de los celos. Puntualiza que los efectos del maltrato pueden persistir más allá del período de la adolescencia, alcanzando la vida adulta.

Por otro lado, explica como los chicos malos parecen más divertidos, interesantes y excitantes y presenta un perfil de chico deseado caracterizado por ser consumista y caprichoso, inalcanzable, ejercer poder emocional, presentar falta de empatía, ser seguros y capaces de dar un estatus a la chica con la que esté, y tener un buen físico. De otro lado, comenta como las chicas ejercen el poder a través de su sexualidad. 
De las relaciones afectivo-sexuales actuales destaca el hecho de que chicos y chicas adolescentes utilicen el número de whatsapp recibidos y la inmediatez con que lo reciben como medidas de pasión e interés definiendo, a partir de las mismas, si se trata de un amor verdadero o de un pasatiempo. Además, destaca como la afectividad en esta situación queda relegada, entendiéndose las emociones de un modo diferente al que se había hecho hasta ahora, promoviendo estados amorosos que oscilan con rapidez.

Atribuye la casuística de la violencia de género por un lado al medio social, que presenta las relaciones como mercancía, y por otro a diversas disfunciones en la familia de origen, como los vínculos débiles entre ella, dificultades de apego o los modelos que los padres representan para los chicos y las madres para las chicas. En concreto, en el caso de las chicas, destaca como situaciones anteriores tales como haber sido víctimas anteriormente, testigo de situaciones violentas en la familia o la justificación de la violencia como derecho de los chicos hace que permanezcan este tipo de relaciones.

En determinados apartados del libro, la autora se centra en la descripción de sintomatologías psicológicas explicando, por ejemplo, como la presencia de síntomas depresivos relacionados con la percepción del propio cuerpo y la baja autoestima puede ser un foco de riesgo de relaciones de amistas y pareja abusivas. Por otro lado, relaciona las conductas machistas y el trastorno disocial.

A lo largo del libro se van presentando fragmentos de entrevistas realizadas a chicas jóvenes que ejemplifican las explicaciones. Se ofrece, entre otras, listas de señales que demuestras que una chica está en situación de riesgo, las creencias que sostienen el machismo entre chicos y chicas adolescentes o las manipulaciones más comunes hoy en día. Señala además como tema pendiente de estudio el por qué las chicas aceptan ser cosificadas por sus parejas.

Un elemento característico de todo el libro es la apelación a la necesidad de la implicación de familias, escuela y entidades dedicadas a la infancia, en la educación, que suponga un cambio pedagógico redirigido a la reflexión, la aceptación del propio cuerpo, que mejore la comprensión de las causas de las relaciones violentas y que ayude a construir un amor 
858 Carmen Martín Gómez - El nuevo ideal del amor en adolescentes digitales [Book Review]

inteligente. Además, puntualiza como desafío prioritario la educación afectiva, proponiendo estrategias de cómo realizarla.

Carmen Martín Gómez, Universidad Loyola Andalucía cmartin@uloyola.es 